\title{
THE OSTEOPOROSIS OF CUSHING'S SYNDROME
}

\author{
H. A. Sissons, London, England
}

From the Institute of Orthopaedics

In 1932 Cushing published a series of cases showing an interesting syndrome which he termed "pituitary basophilism" and which he ascribed to a pituitary adenoma of basophil cells. Cushing's patients, all young adults, showed the following clinical features: an unusual type of increase in subcutaneous fat, involving the face, neck and trunk; osteoporosis of the skeleton, most marked in the spine, resulting in kyphosis and diminution of stature; amenorrhoea in females and ultimate impotence in males; hirsutism involving the face and trunk in females; atrophic skin with purplish striae; hypertension; diabetes; and polycythaemia.

The condition, now known as Cushing's syndrome, has been the subject of many detailed clinical and endocrinological studies in recent years. It has become apparent that the syndrome can be associated with hyperplasia or tumour formation of the adrenal cortex in the absence of a pituitary adenoma (see for example Lescher and Robb-Smith 1935). In fact Albright (1943), reviewing work in this field, ascribed the various manifestations of Cushing's syndrome to hyperadrenocorticism, with or without a basophil adenoma of the pituitary. He put forward the view that the over-production of an adrenal hormone is responsible for inhibition of protein synthesis throughout the body, and contrasted the metabolic position with that in the adreno-genital syndrome, where different adrenal hormones are concerned, including one normally responsible for the development of pubic and axillary hair.

Cushing's original account noted that bone changes were present in six out of eight cases coming to autopsy. While the clinical and radiological aspects of the osteoporosis of the spine are now well known, there is little published information on the structural pathology of this lesion or of other skeletal changes in Cushing's syndrome. The present paper, therefore, describes the histological changes in bone in autopsy material from four examples of this condition. (The cases are arranged in order of increasing severity of skeletal changes, but the illustrations are arranged in a different order to show particular aspects of the cases side by side: Topographical photographs and radiographs of the vertebral column in Case 4 are followed by low-power histological preparations from the individual cases, then by high-power photomicrographs of the abnormal bone tissue, and finally by pictures of repairing fractures in the individual cases.)

\section{CASE REPORTS}

Case 1 (case reported by Maclay, Stokes and Russell 1938)-The patient was a woman aged twenty-nine years, with a history of increasing virilism for three years, associated with depressive mental changes. Glycosuria and hypertension were present but neither signs nor symptoms referable to the skeleton were noted.

At post-mortem examination there was no pituitary adenoma, but hyaline change of the basophil cells was observed. The cortex of each adrenal was hyperplastic. The changes of congestive cardiac failure were present.

The spine showed osteoporosis. The general outline of vertebral bodies and of intervertebral discs was normal (Fig. 8). The cortical bone was thinned and presented many small defects where bone marrow was in contact with either periosteum or intervertebral disc tissue. In the cancellous bone all trabeculae were thinner than normal. The horizontally disposed trabeculae were most severely involved by the rarefaction; many were absent and 
the remaining trabeculae were thus predominantly vertical in their arrangement. The vertebral bodies contained considerable amounts of haemopoietic marrow, although histological examination showed an increased number of fat cells (Fig. 11). The slender trabeculae had a normal histological structure, consisting of lamellar bone in which each lamellar system was

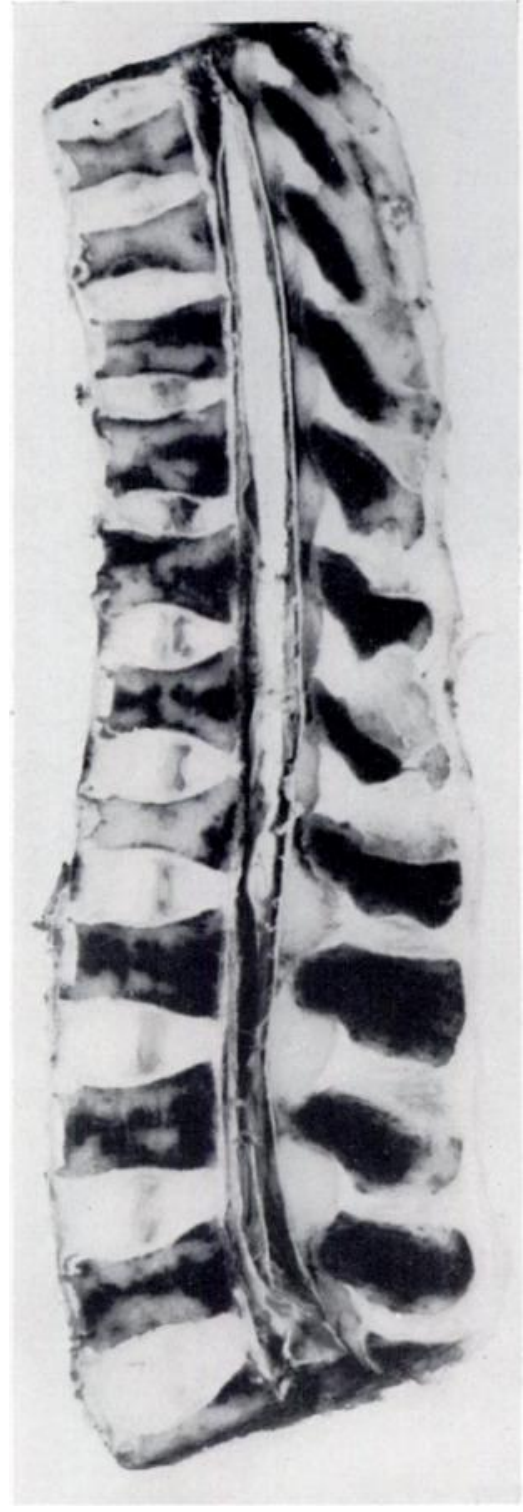

FIG. 1

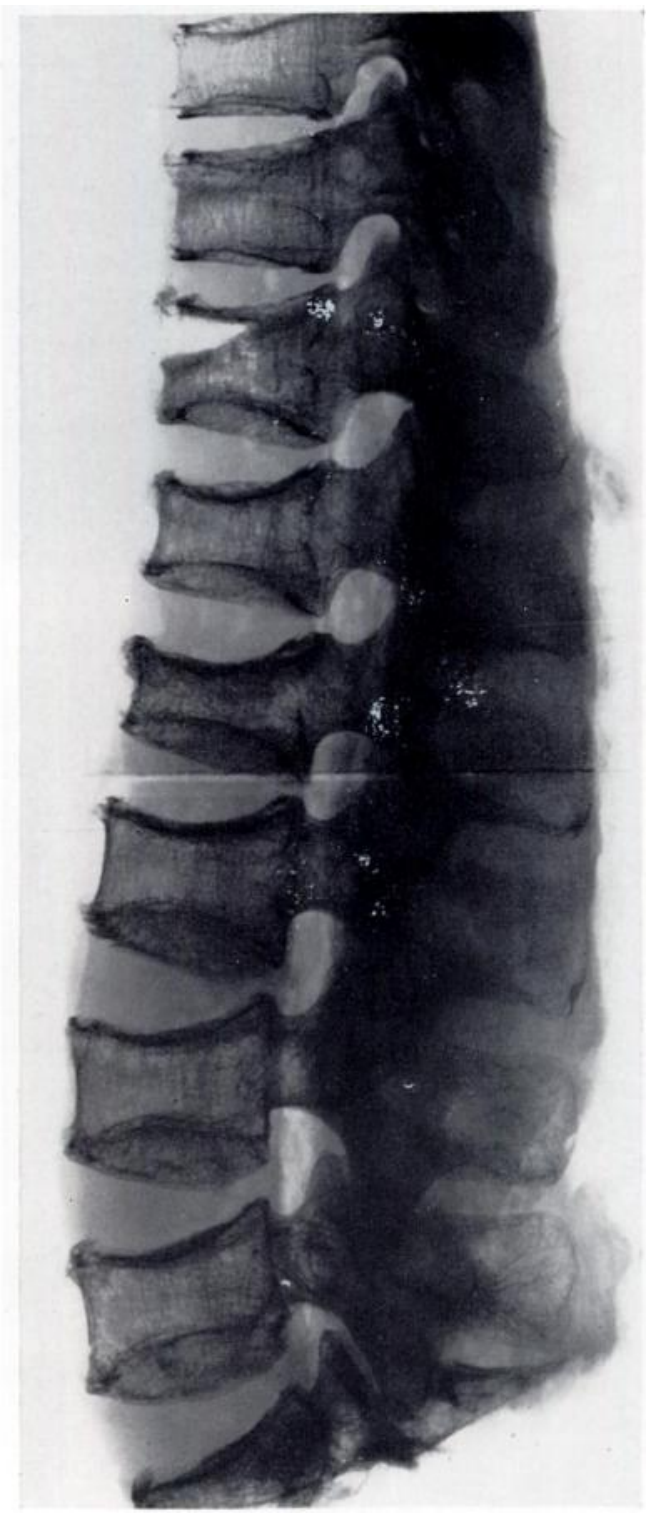

FIG. 2

Case 4. Figure 1-Photograph of the thoracic and lumbar spine divided longitudinally, showing compression of the anterior parts of the vertebral bodies with expansion of the intervertebral disc tissue. Haemopoietic marrow is replaced by fat in many of the vertebral bodies. Figure 2-A radiograph of the specimen shown in Figure 1, but omitting the upper two vertebrae.

bounded by normal cement lines. Osteocytes and osteoblasts appeared normal. Narrow osteoid borders were seen on the surfaces of a small number of bone trabeculae, and the presence of scattered areas of focal erosion of the trabecular surfaces indicated active, though not excessive, osteoclastic bone resorption.

VOL. $38 \mathrm{~B}$, NO. 1, FEBRUARY 1956

$2 \mathrm{Bl}$ (w) 
In histological sections the ribs showed a considerable degree of osteoporosis and contained rather fatty bone marrow. There were some spontaneous fractures and these show developing callus (Figs. 19 to 21). In what appeared to be a very recent fracture there was active bone formation but little vascular reaction (Fig. 20), while in several older fractures the callus tissue was at an unusually quiescent stage despite the incompleteness of bony union.

Sections of the femoral shaft showed slight osteoporosis which took the form of patchy thinning of the cortex, evidence of bone destruction being particularly evident on the endosteal surface. Other bones were not studied.

Case 2-The patient was a woman aged thirty-three years.

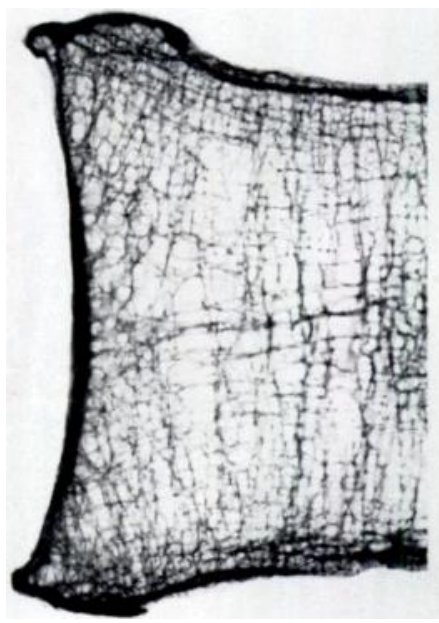

FIG. 3

Radiograph of a slab of bone from a normal vertebra for comparison with Figures 4 to 6 . $(\times 2$.) There was a history of amenorrhoea, hirsutes and increase in weight, with evidence of glycosuria, hypertension and renal insufficiency. Radiographs of the skeleton showed osteoporosis of the spine, ribs, and long bones. Several ribs showed fractures with formation of callus, but there was no evidence of collapse of any of the osteoporotic vertebral bodies. Death was due to uraemia and malignant hypertension.

At post-mortem examination the pituitary contained a basophil adenoma 6 millimetres in diameter; microscopically a conspicuous degree of hyaline change affected the remaining basophil cells. The adrenals, which together weighed 16.3 grammes, were of unequal size, the right being partly destroyed by old infarcts. There was great cortical hyperplasia in the left adrenal cortex and in the residual parts of the right cortex.

The spine showed osteoporosis. The general outline of vertebral bodies and of intervertebral discs was normal, but the extent of bony rarefaction was more pronounced than in the previous case (Fig. 9). The cortical bone was very incomplete, particularly on the upper and lower surfaces of the vertebrae, although the general contour of the vertebral bodies was unchanged. In the cancellous bone rarefaction involved both vertical and horizontal trabeculae. There was considerable replacement of haemopoietic marrow by fat cells, which were often arranged along the surfaces of bone trabeculae (Fig. 12). Osteocytes and osteoblasts appeared normal despite diminished osteoblastic activity; the trabeculae were almost completely devoid of osteoid borders. Occasional areas of localised erosion of the trabecular surface indicated continuing. though not excessive, osteoclastic bone resorption (Fig. 12).

In histological preparations the ribs showed marked osteoporosis and contained fatty bone marrow. Material from a spontaneous rib fracture showed developing callus, but although union was incomplete the repairing tissues were at a quiescent stage (Figs. 22 and 23). Thus in Figure 22 the periosteal callus was seen to consist of inactive bone devoid of either osteoid borders or conspicuous osteoblastic activity; Figure 23 showed inactive fibrocartilaginous callus with little vascularisation or bony replacement.

Sections of femur, pelvis and skull showed slight osteoporosis which took the form of irregular thinning of the cortical bone.

Case 3 (case reported by Lescher and Robb-Smith 1935)-The patient was a woman aged thirty-five years. There was a history of hirsutes, hypertension and glycosuria, together with increasing weight over a number of years. Spinal osteoporosis with collapse of dorsal vertebrae became apparent, and a number of spontaneous rib fractures developed. A large adrenal "cortical cell carcinoma" was present, and the patient died soon after its removal. 


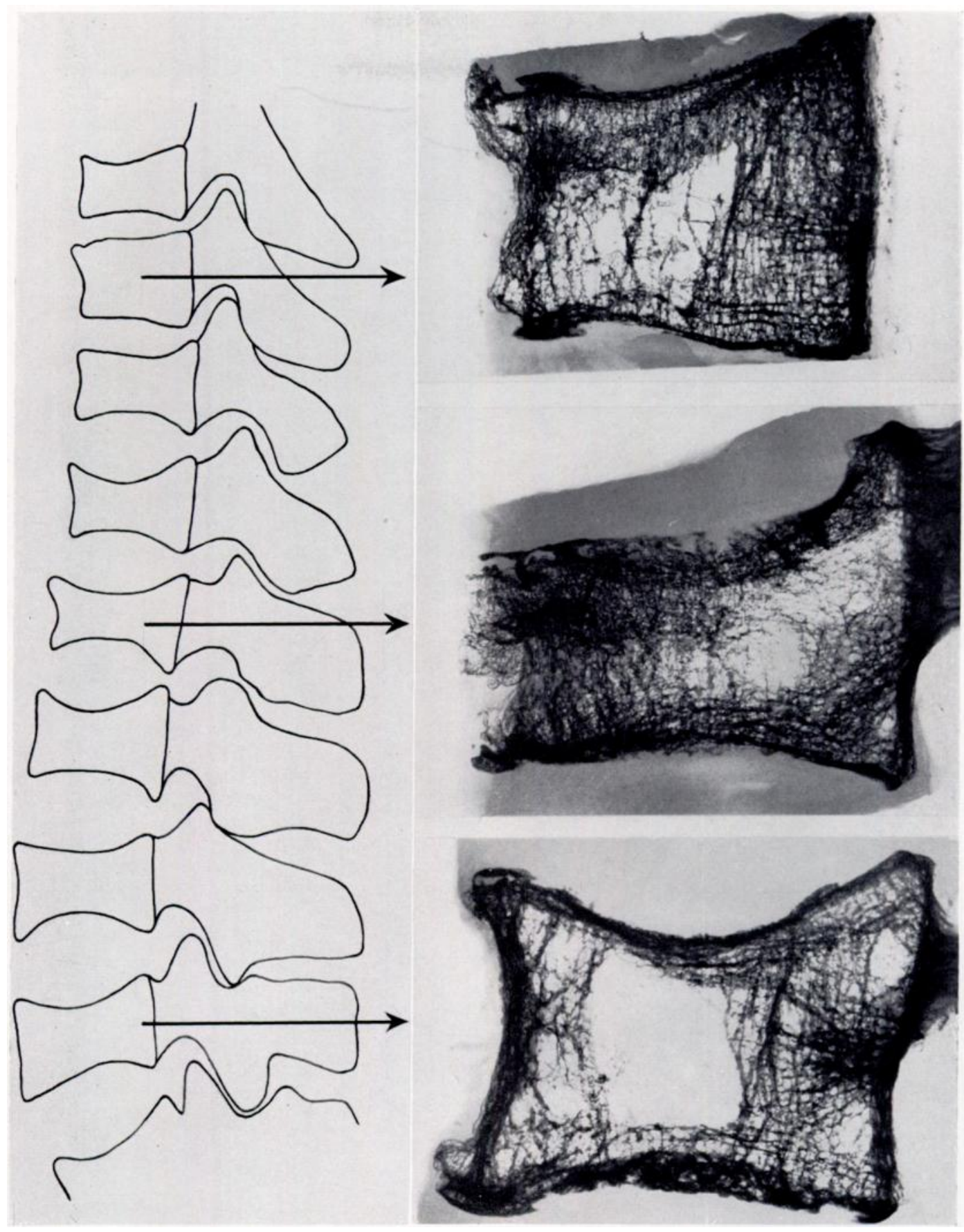

Figs. 4, 5 and 6

Case 4-Radiographs of bone slabs from three of the vertebral bodies shown in Figures 1 and 2. ( $\times 2$.) Cortical bone is almost completely absent from the osteoporotic vertebrae; the normal cancellous bone is replaced by an incomplete network of irregular trabeculae, which are often greatly reduced in thickness. The anterior and upper parts of two of the vertebral bodies show collapse of the osteoporotic bone structure. 

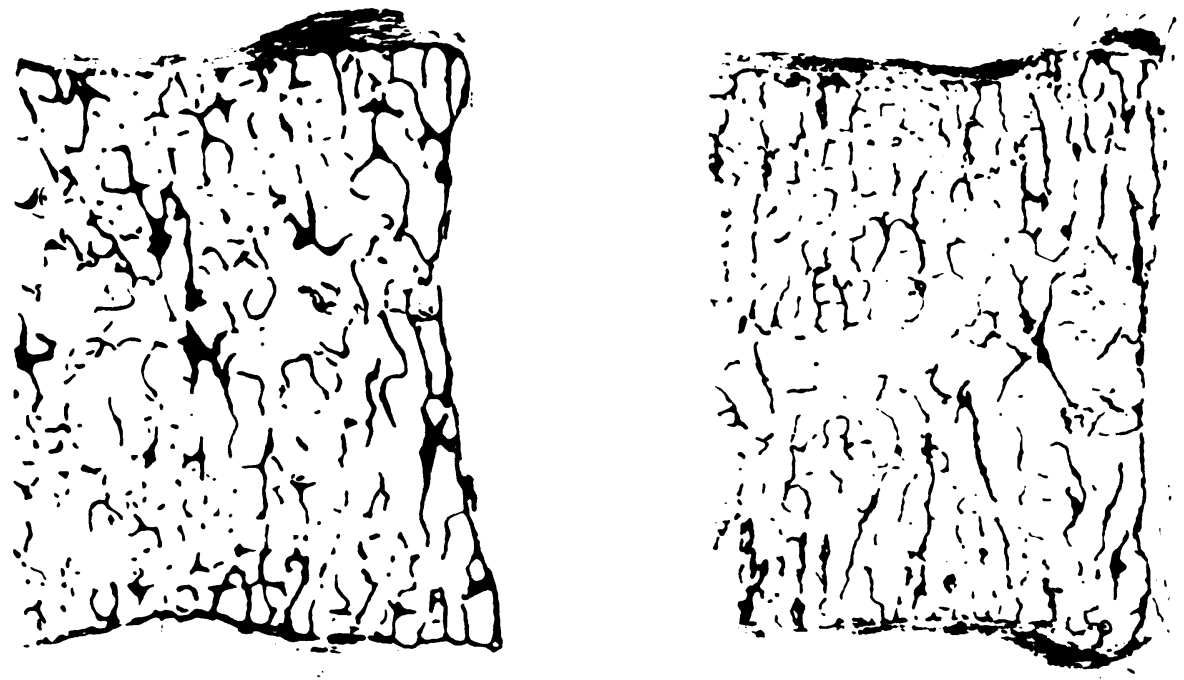

Fig. 7

Fig. 8

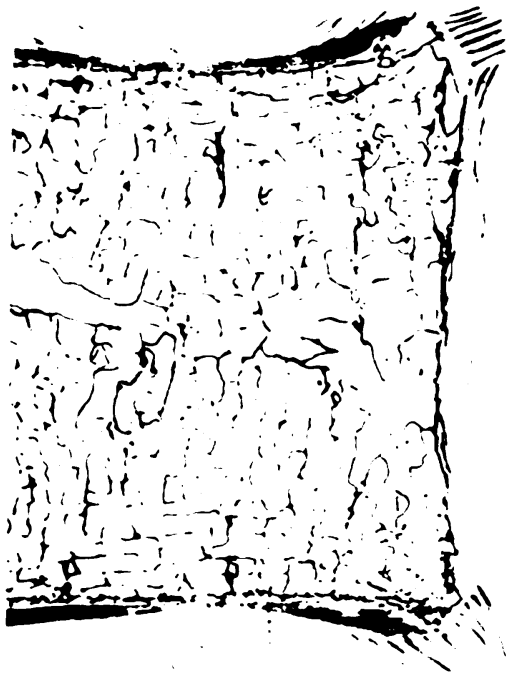

FIG. 9

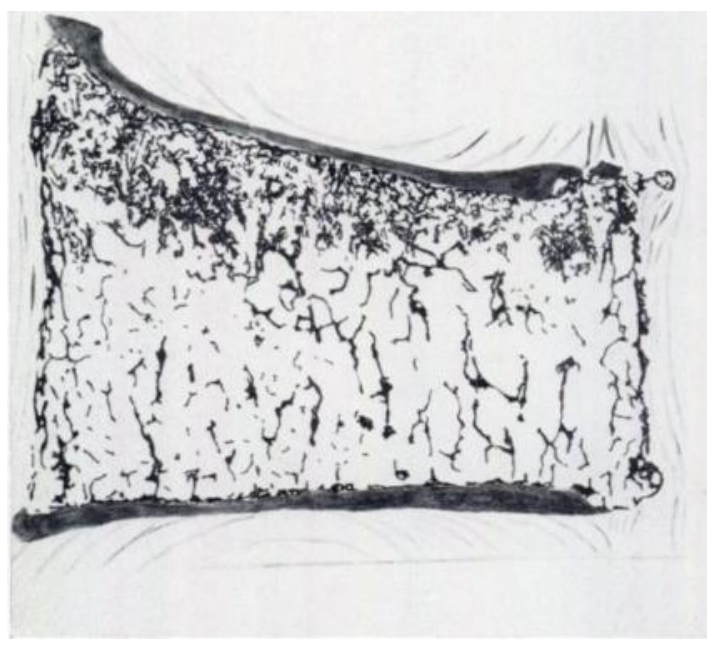

FIG. 10

Outline drawings of the bony structure of vertebral bodies as seen in histological sections. $(\times 2$.) Figure 7-Normal structure. Figure 8 (Case 1) and Figure 9 (Case 2) show a diminution in thickness of bone trabeculae. Figure 10 (Case 3)-There is, in addition to this change, compression of the upper part of the vertebral body. Numerous slender newly formed bone trabeculae can be seen in the area of collapse. 
At post-mortem examination no metastases were found. The pituitary showed some increase in basophil cells; at one point these formed a small collection 0.3 millimetre in diameter. Extensive hyaline changes in the basophils in this case were reported by Crooke (1935).

The spine showed osteoporosis with collapse of a number of vertebral bodies (Fig. 10). In addition to the general rarefaction of the cortical and cancellous bone, it was evident that the upper surface of the vertebral body illustrated had been displaced downwards with disorganisation of the adjacent tissues. The bone of the lower part of the body was not affected by this compression and displacement. In vertebral bodies which were not collapsed the slender bone trabeculae were almost completely devoid of osteoid borders; they showed evidence of continuing, though not excessive, osteoclastic bone resorption. There was considerable replacement of haemopoietic marrow by fat cells. In the collapsed vertebrae, many individual

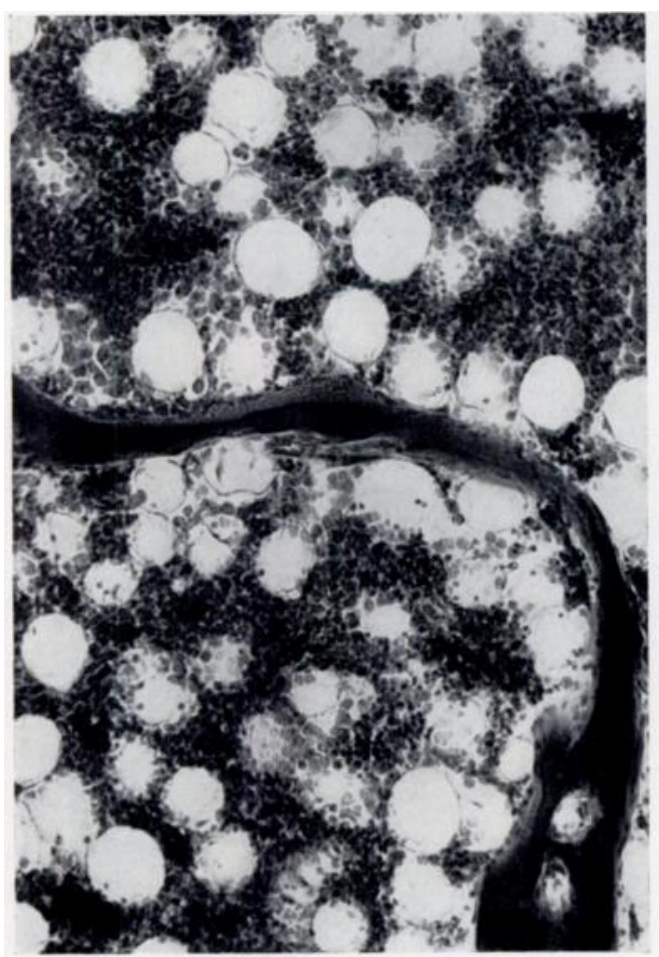

Fig. 11

Case 1-A slender bone trabecula from the central part of a vertebral body showing a narrow osteoid border on its upper surface. $(\times 75$.) The opposite surface of the trabecula presentsaneroded appearance.

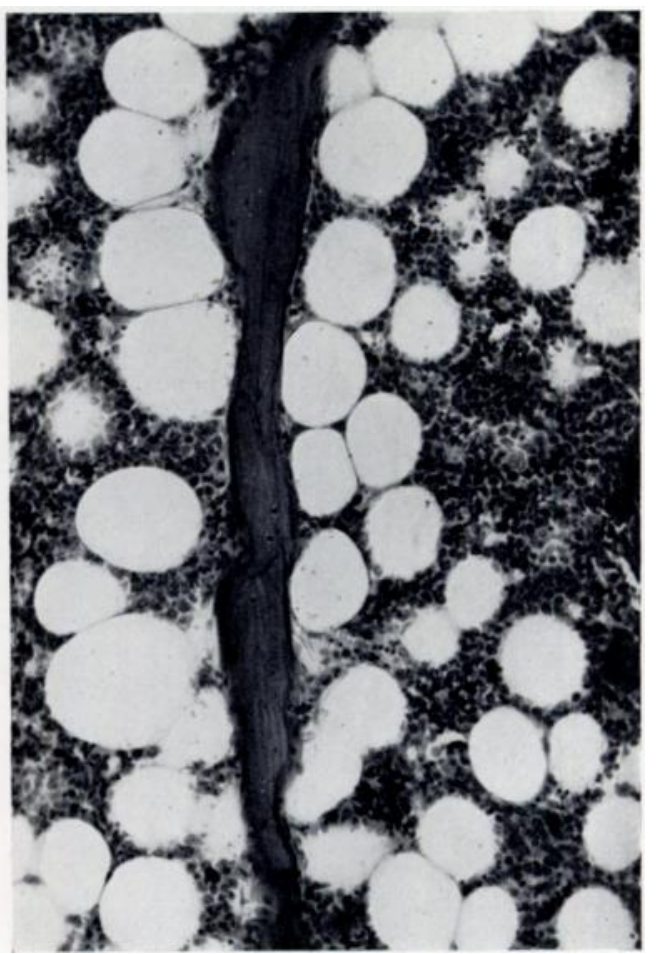

Fig. 12

Case 2-A slender bone trabecula from the central part of a vertebral body. $(\times 75$. $)$ Occasional eroded bays are present on the bone surface, indicating some previous osteoclastic resorption.

bone trabeculae were fractured and displaced (Figs. 16 and 17). In some areas this damage was associated with only minimal tissue reaction, and had not led to any reparative bony changes. In others, seen at a later stage, the displaced trabeculae were surrounded by irregular masses of newly formed non-lamellar bone.

In histological preparations the ribs showed marked osteoporosis and contained fatty marrow. Sections from a spontaneous rib fracture showed some bony union both endosteally and periosteally (Figs. 24 to 26), but the periosteal callus included a considerable amount of abnormal degenerated cartilage and quiescent fibrocartilage with little evidence of vascularisation and bony replacement. As in the previous cases, there was little activity of periosteal bone formation at the peripheral parts of the callus.

No other bones were studied in this case.

VOl. $38 \mathrm{~B}$, NO. 1, FEBRUARY 1956 
Case 4-The patient was a girl aged sixteen years. There was a history of amenorrhoea and of progressive obesity and hirsutes for five years. Three years after the onset of symptoms, severe lumbar pain directed attention to the spine. The patient was admitted to hospital. and spinal osteoporosis with collapse of several vertebral bodies was found. Diabetes and hypertension were present at this stage. Surgical exploration of the adrenals showed symmetrical cortical hyperplasia; the patient's condition temporarily improved after the removal of the left adrenal.

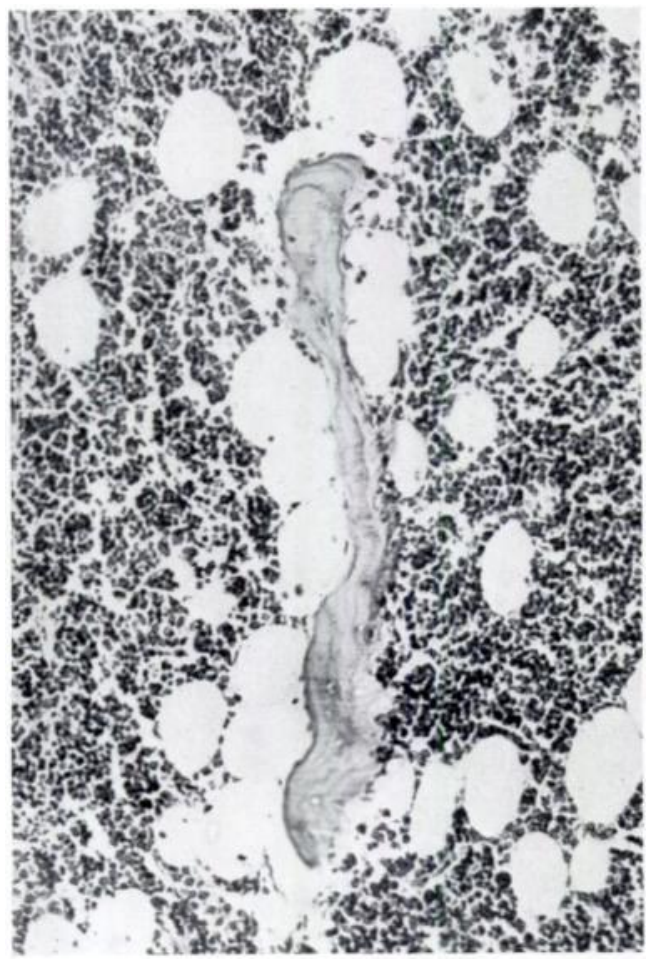

Fig. 13

Case 4-A slender bone trabecula from the central the increased number of fat cells present in the marrow: many of these fat cells are in contact with the surface of the bone trabecula. part of one of the vertebral bodies. (x 75.) Note

At post-mortem examination the pituitary contained a basophil adenoma; microscopically there was a conspicuous degree of hyaline change affecting the remaining basophil cells. Recent haemorrhage had occurred both in the tumour and in the surrounding pituitary tissue. There was some degree of hyperplasia of the cortical tissue of the remaining adrenal.

The spine showed a marked degree of osteoporosis with a varying degree of collapse of a number of vertebral bodies in the lower dorsal and lumbar region (Figs. 1 and 2). The contour of the vertebral bodies was changed. the concavity of the upper and lower surfaces being greatly exaggerated with a corresponding "ballooning" of the intervertebral discs. In collapsed vertebrae it was the anterior part of the body which was affected. The extreme rarefaction of cortical and cancellous bone became evident when Figures 4 to 6 -radiographs of bone slabs from vertebral bodies in this casewere compared with Figure 3, which showed a similar preparation from a normal vertebral body. Some areas of the abnormal vertebral bodies were completely devoid of bone trabeculae, while those trabeculae present in other areas were abnormally slender. They were often angulated, and irregular and crenated in outline. In all the vertebrae there was considerable replacement of haemopoietic marrow by fat, this being most apparent in the areas where bony rarefaction and collapse were most marked (Fig. 1). The surfaces of the slender bone trabeculae of the osteoporotic vertebral bodies were completely devoid of osteoid borders (Fig. 13). Although such osteoblasts as were present were histologically normal, their number was very much diminished, and their total bone-forming activity was clearly reduced. There was evidence of continuing, but not excessive, osteoclastic bone resorption, although osteoclasts themselves were rare. The cortical bone in the vertebral bodies, as well as being greatly thinned (Fig. 14), presented many small defects (Fig. 15) where the bone marrow was in contact with either periosteum or intervertebral disc tissue. Despite the changed contour of the upper and lower surfaces of vertebral bodies, the line of junction between the bone and the adjacent intervertebral disc tissue was smooth. Bone formation extended into the cartilage of the intervertebral disc in some areas, as was evident in the radiographs of bone slabs shown in Figures 4 to 6 , but the general contour of the bone surface is not interrupted.

In the collapsed vertebrae there were numerous fractures of individual trabeculae. In most areas the reaction of the adjacent tissue to recent trabecular fractures was minimal, 
although in one vertebra the displaced trabeculae in the collapsed area were surrounded by vascular granulation tissue and proliferating osteoblasts. Despite the minimal reaction, the fractured and displaced trabeculae eventually became bound together into irregular masses of bone (Fig. 18). The structural changes in these vertebrae (see for instance Figures 2. 4. 5 and 6) indicate that "collapse" of the osteoporotic bone structure may take place quietly and continuously, but that this process can sometimes be interrupted by a sudden and more complete compression fracture.

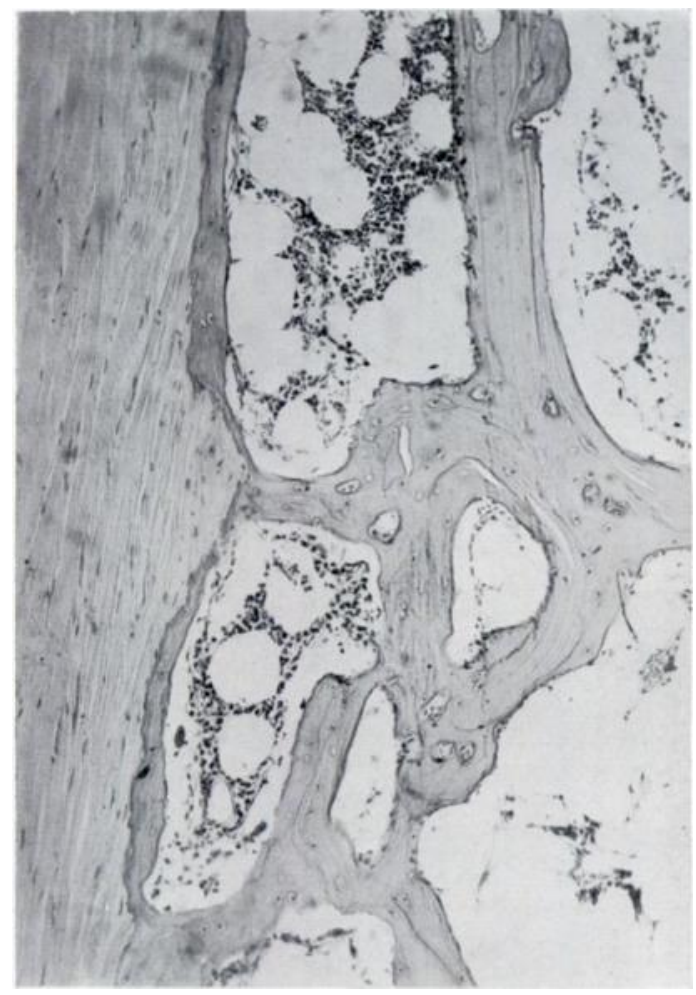

Fig. 14

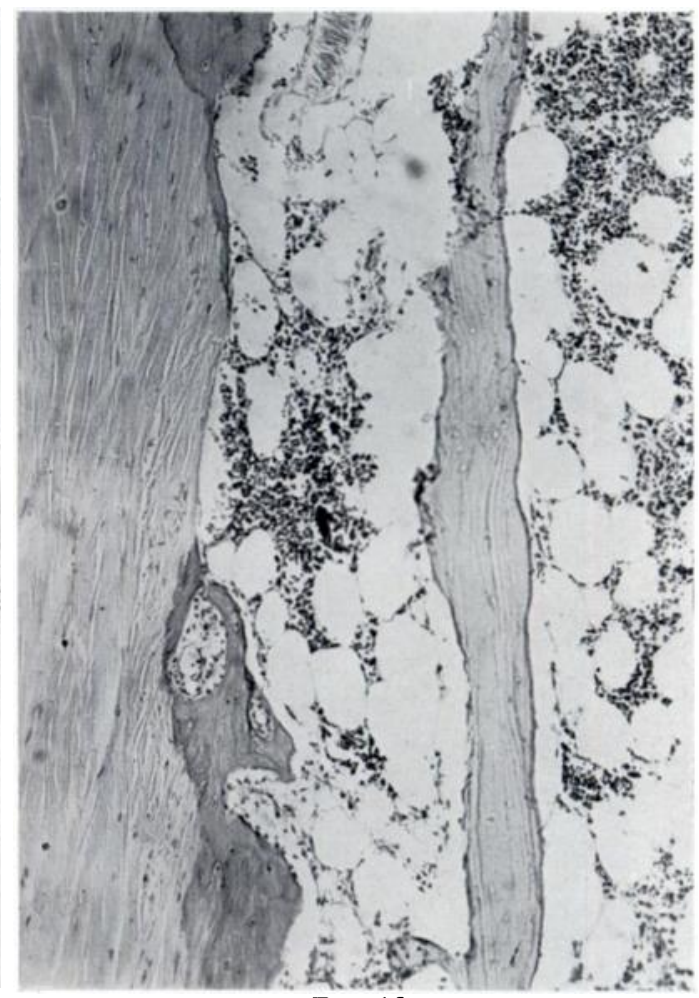

Fig. 15

Case 4-Areas from the rarefied cortical bone of the anterior wall of a vertebral body, showing extreme narrowing of the bone and the contact between bone marrow and periosteal fibrous tissue in some areas. $(.75$.)

Sections of the ribs showed osteoporosis, both the cortical bone and the medullary trabeculae being thinner than normal. Sections of femoral shaft showed slight osteoporosis in the form of patchy thinning of the cortical bone. Sections of the vault of the skull did not show any histological abnormality.

\section{DISCUSSION}

In 1920 Mooser included a detailed description of bone changes in his account of the post-mortem findings in a case of "obesity with osteoporosis" which Cushing recognised as comparable with his own cases. Mooser showed that the bone change was indeed osteoporosis, described the collapse of vertebral bodies without evidence of acute fracture. and noted that evidence of exaggerated osteoclastic bone destruction was lacking. The vertebrae in the case he described showed unusual herniations of bone marrow into adjacent degenerated and calcified intervertebral disc tissue, and also herniations of disc tissue into the vertebral bone marrow that would now be described as Schmorl's nodes. In 1933 Rutishauser noted and described the osteoporosis present in two cases of Cushing's syndrome coming to post-mortem examination, each case being associated with a pituitary adenoma. More recently Follis (1951 $a$ ) has described bone changes in five cases of Cushing's syndrome studied 


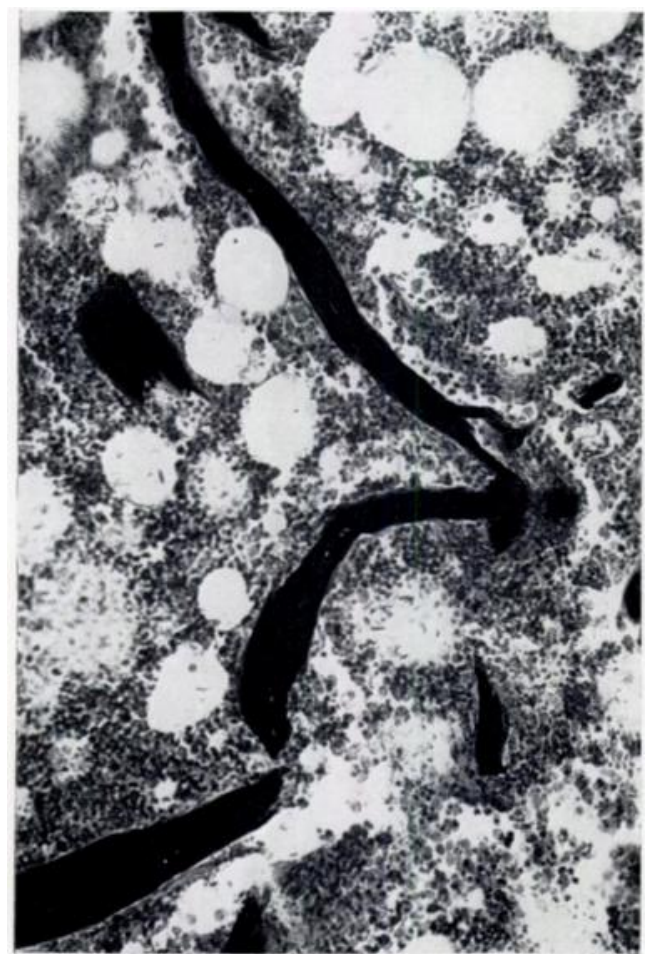

Fig. 16

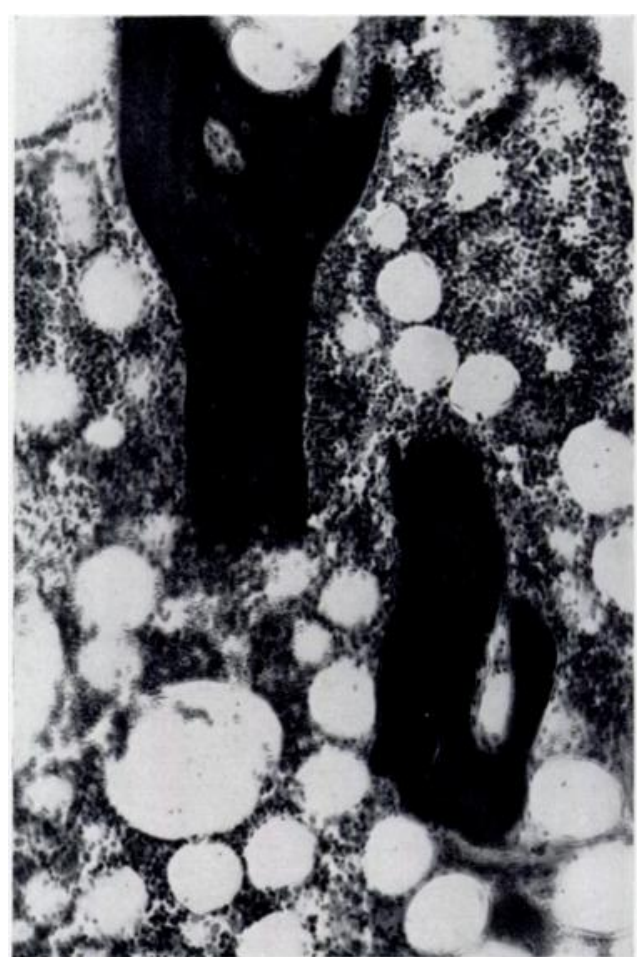

FIG. 17

Case 3. Figure 16-Fractured bone trabecula at the margin of the area of collapse in the vertebral body shown in Figure 10. ( $\times 75$.) Reaction of the adjacent tissues is minimal. Figure 17-Another fractured bone trabecula from the collapsed area of the vertebral body shown in Figure $10 .(\times 75$.) Some displacement has occurred, but again the reaction of the adjacent tissues is minimal.

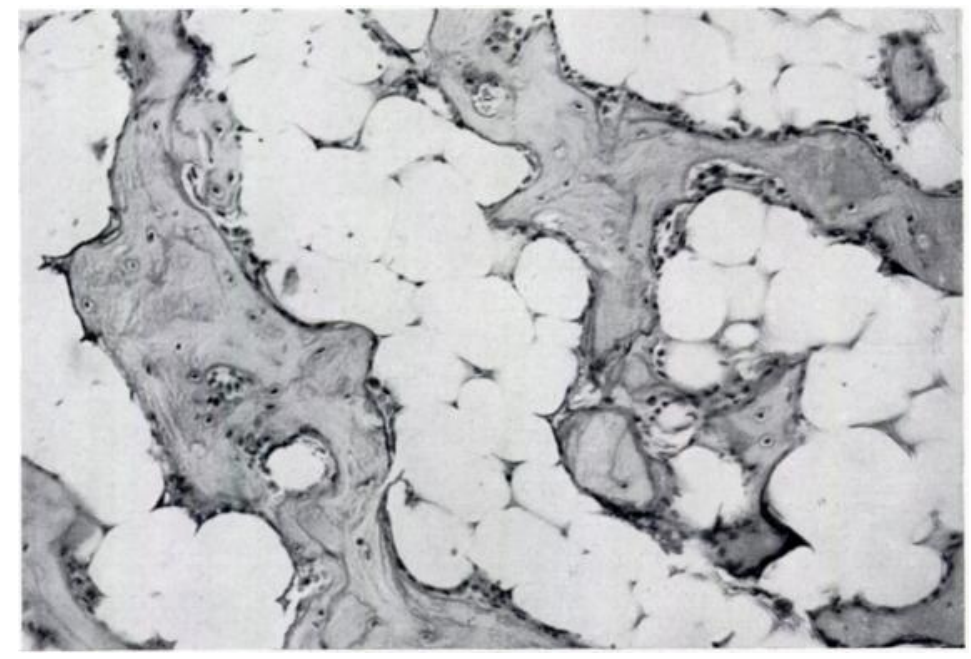

FIG. 18

Case 4-Bone trabeculae in the collapsed area of the vertebral body shown in Figure 5. $(\times 75$.$) The appearances suggest that slender trabeculae in the$ collapsed region have become impacted, and have been surrounded by newly formed bone to produce thicker structures. 


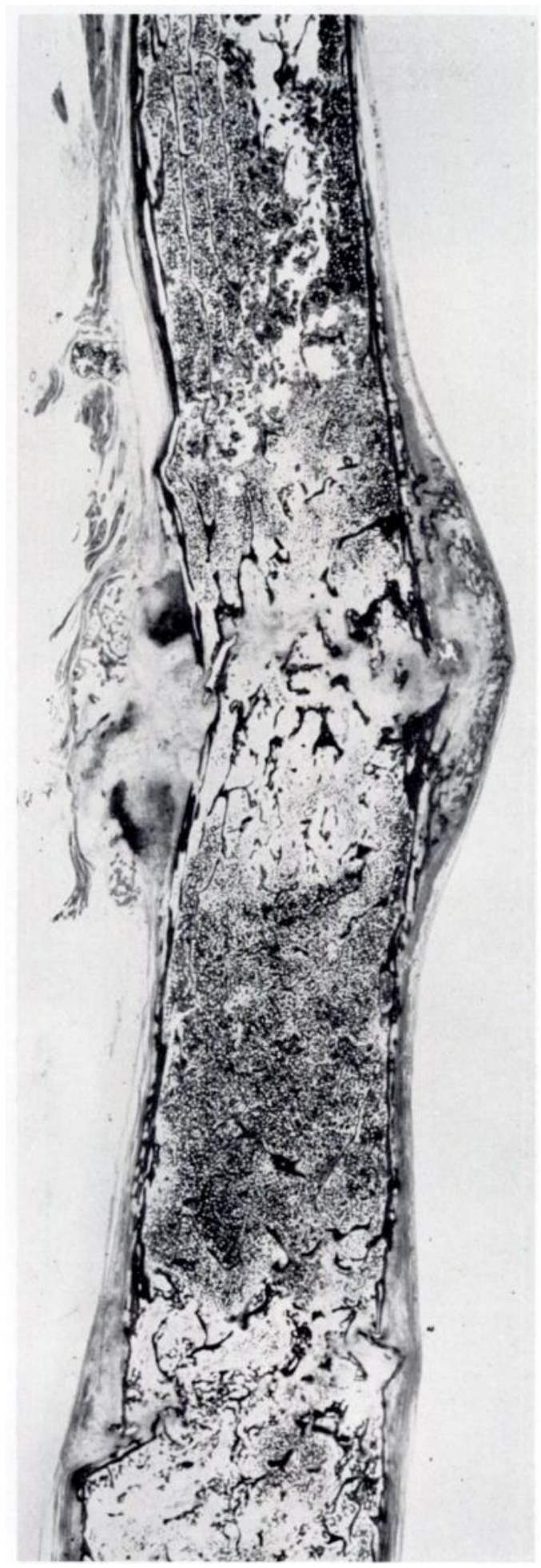

FIG. 19

Case 1-A histological preparation of a rib showing two recent and incompletely united spontaneous fractures. The larger one is centrally placed and is surrounded by periosteal callus; the other is toward the bottom of the figure and shows neither displacement of the bone nor periosteal callus. 


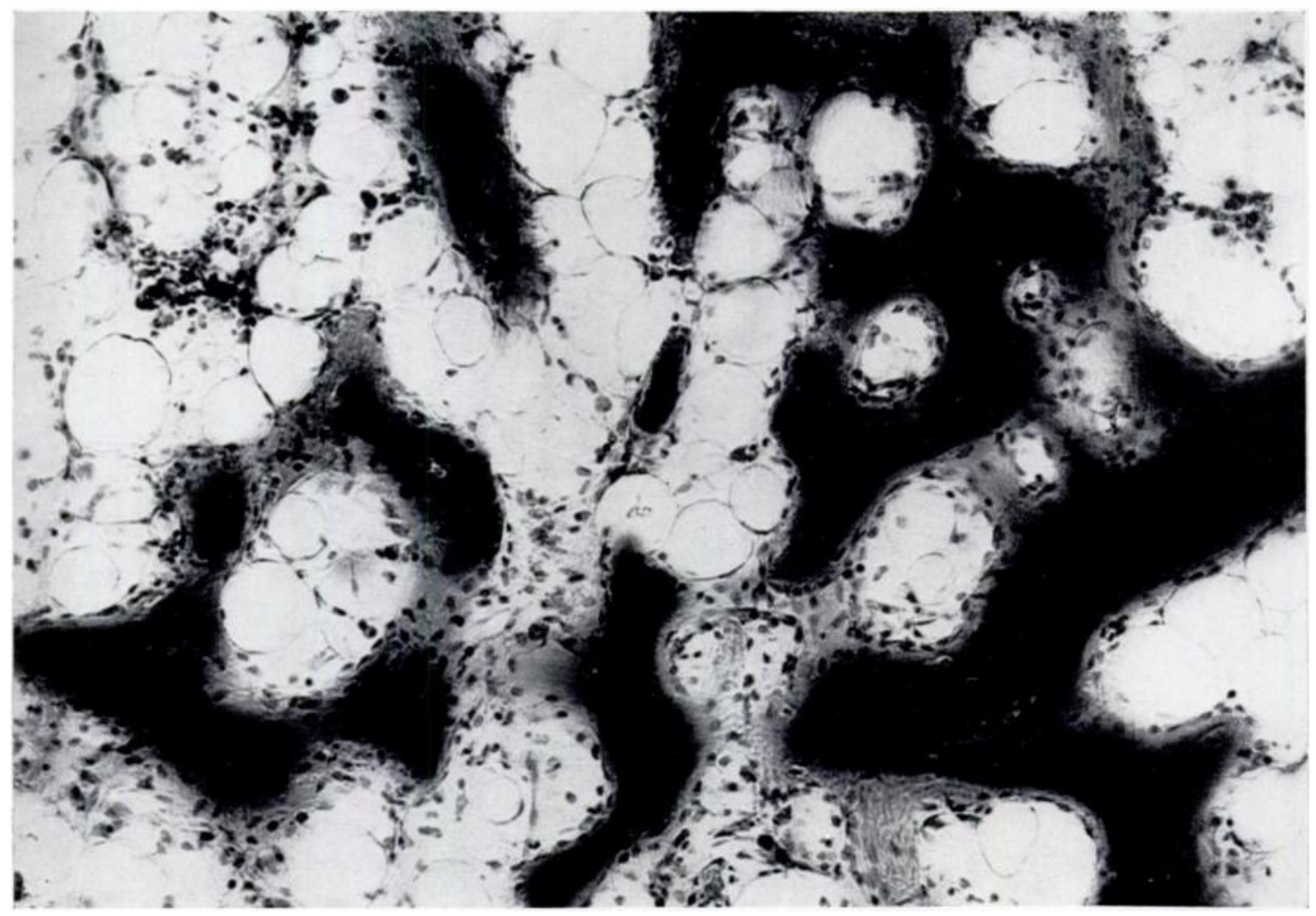

FIG. 20

Case 1-Showing active osteoblastic bone formation in the endosteal callus of the smaller and very recent fracture in Figure 19. $(\times 160$.

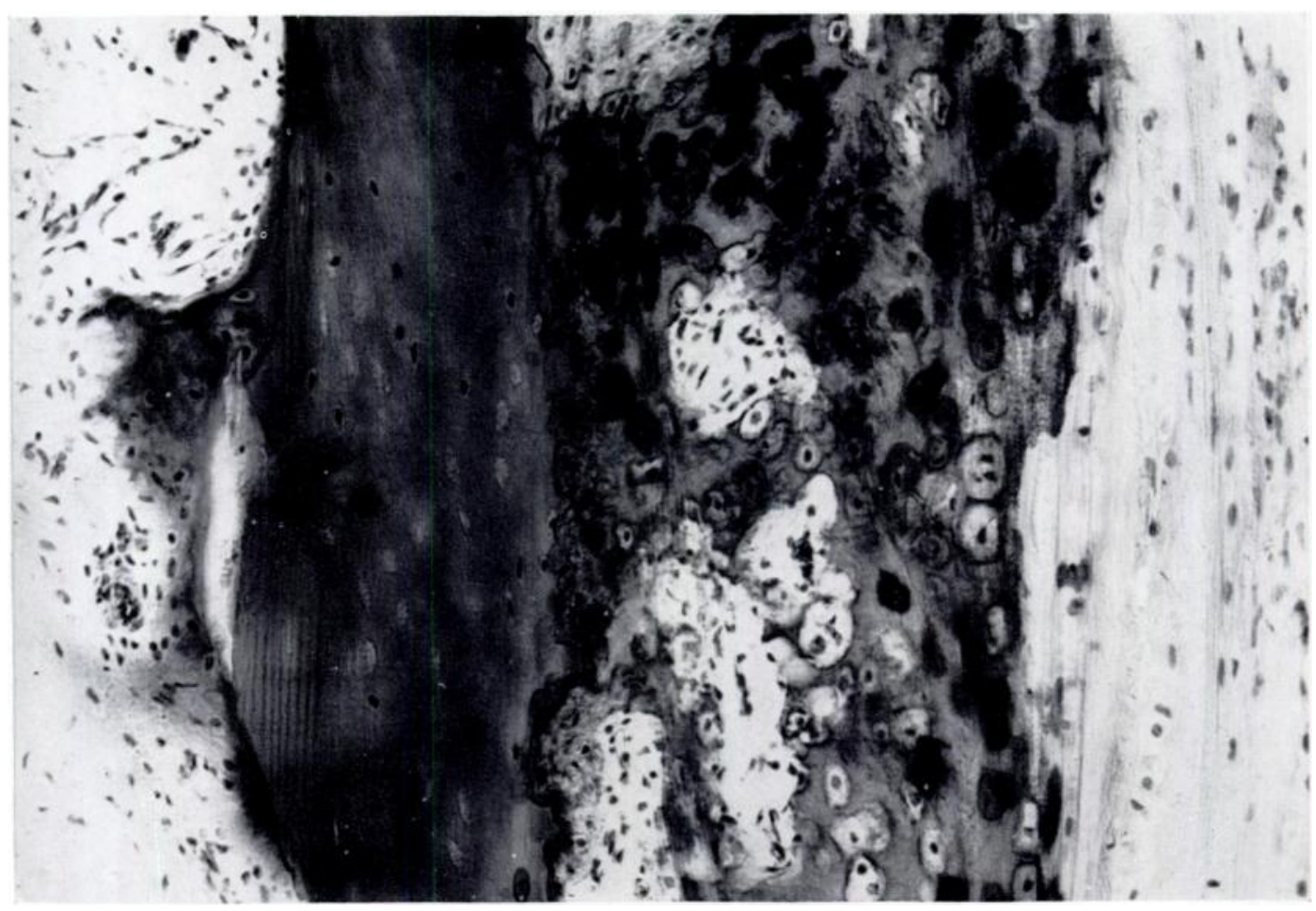

FIG. 21

Case 1-Showing less active periosteal callus from the larger and older fracture in Figure 19. $(\times 160$.) 


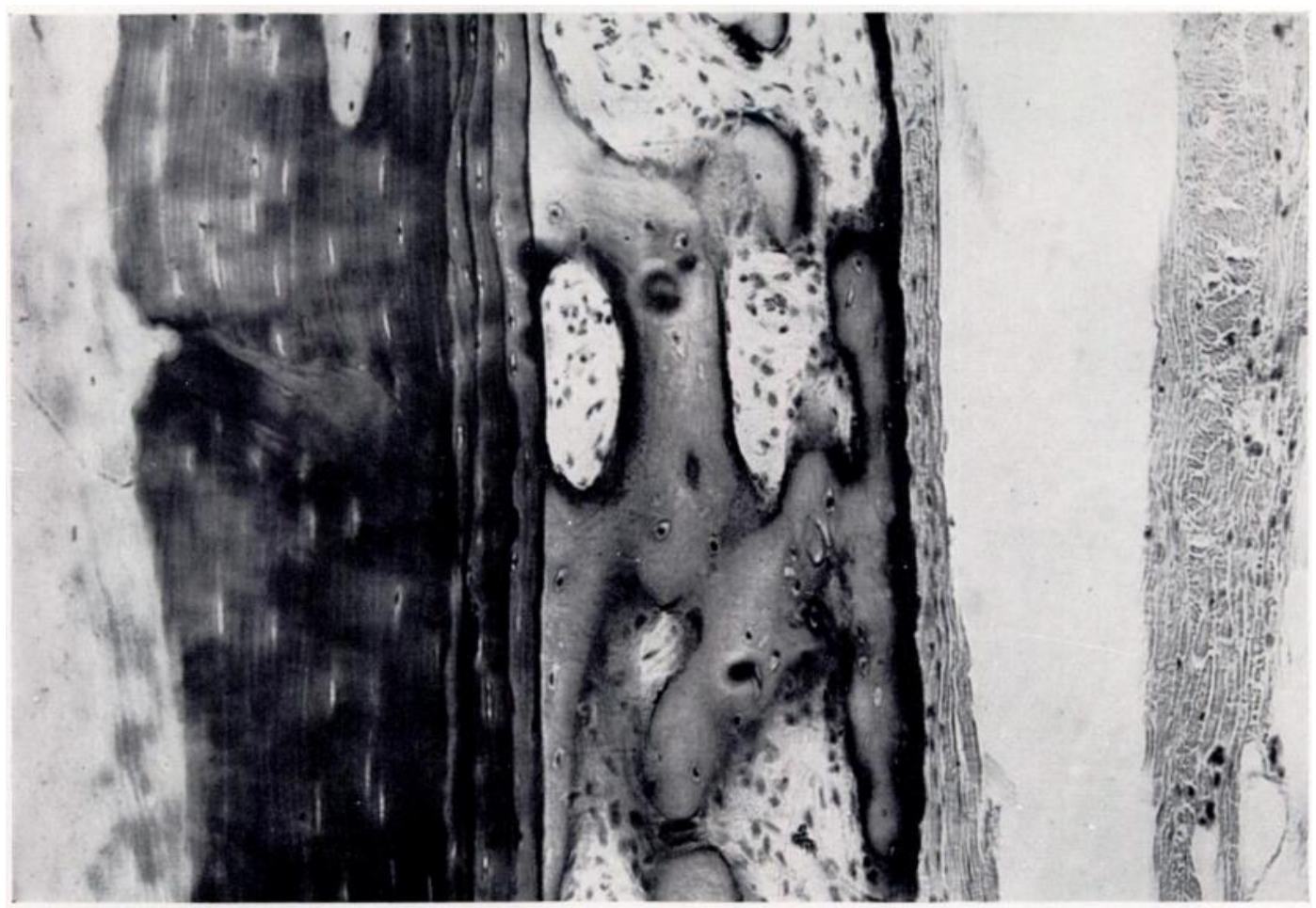

FIG. 22

Case 2-Inactive periosteal callus from spontaneous fracture of rib. $(\times 160$.$) Few osteoblasts are present on$ the surface of the newly formed bone.

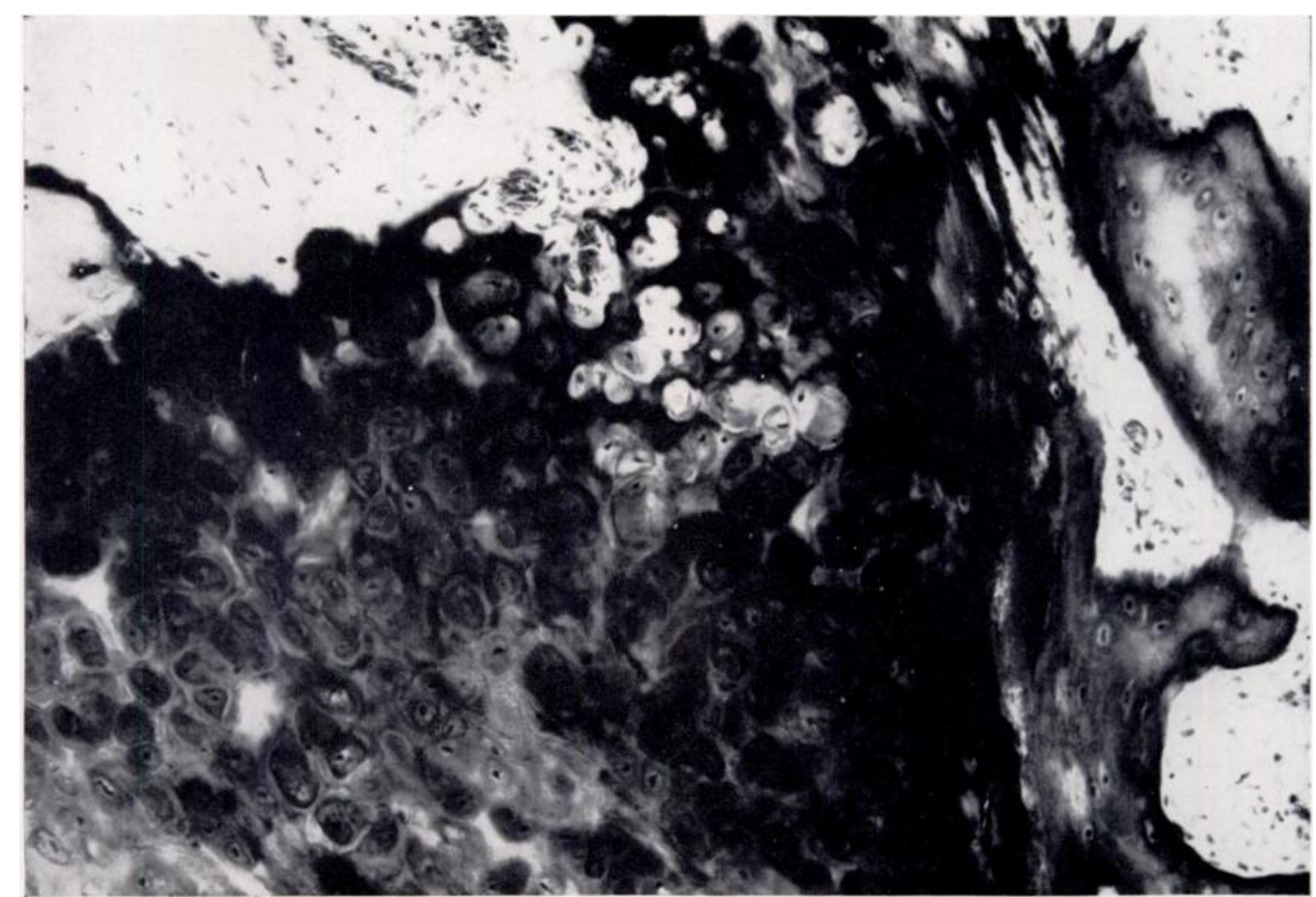

FIG. 23

Case 2-Inactive periosteal callus from spontaneous fracture of rib. $(\times 160$. $)$ The field shown consists of unusual fibrocartilaginous callus showing only minimal vascularisation.

VOL. $38 \mathrm{~B}$, NO. 1, FEBRUARY 1956 


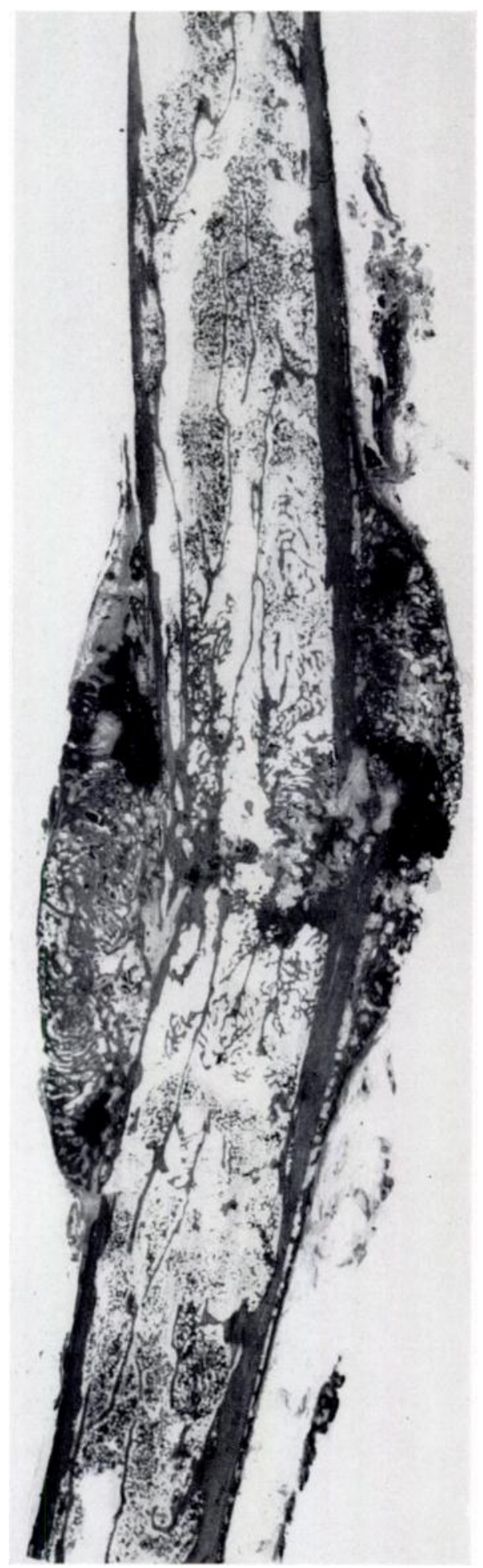

FIG. 24

Case 3-A histological preparation of a rib showing a spontaneous fracture. $(\times 4$.) The progress of union is seen at a later stage than in Figures 19 to 21 . Both periosteal and endosteal bony callus are uniting the bone ends. 


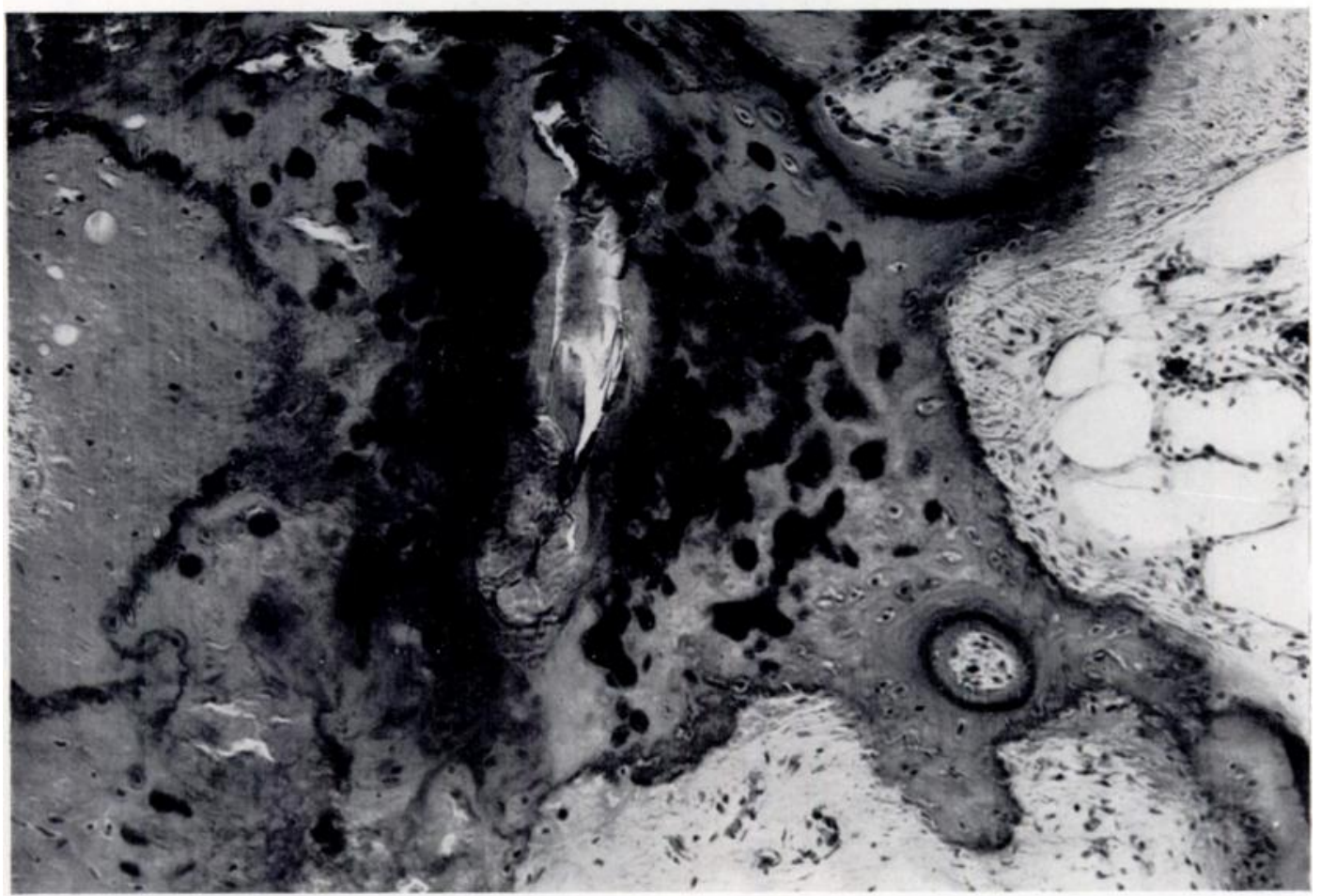

FIG. 25

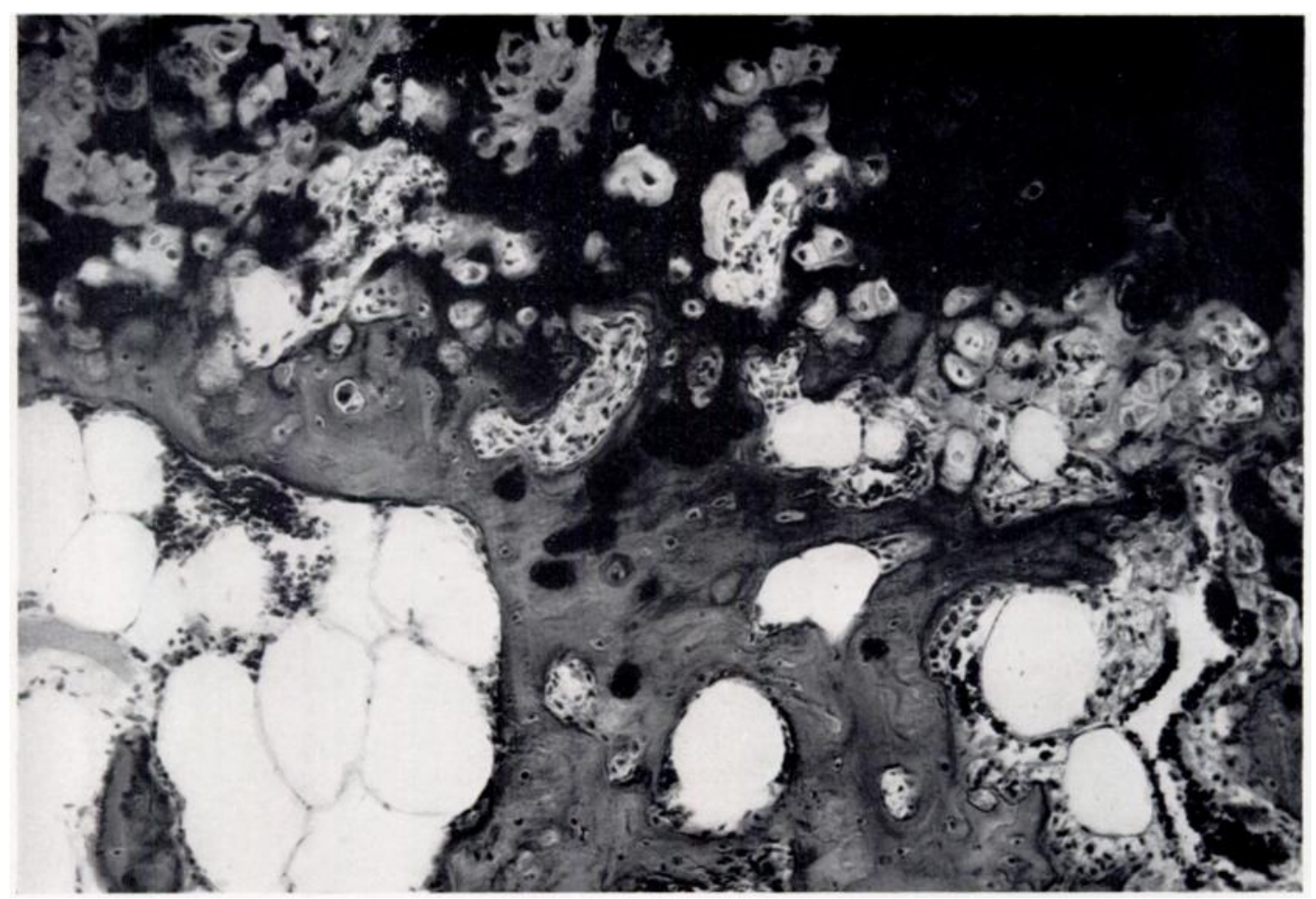

Fig. 26

Case 3-Further preparations of the specimen seen in Figure 24. $(\times 160$.) Unusual degenerate and fibrocartilaginous callus is seen, with little vascularisation and bony replacement.

VOL. 38 B, NO. 1, FEBRUARY 1956 
at post-mortem. In four adult cases he found osteoporosis. Osteoid borders were occasionally seen, but osteoclasts were not observed. In his fifth case Follis recorded the changes in growing epiphysial cartilage in a "Cushing-like" condition in an infant of fifteen months. These took the form of growth arrest and disorganisation of cartilage tissue.

The changes described in the vertebral bodies in the present series of cases are substantially those of the accounts mentioned above. The abnormalities of fracture repair noted do not appear to have been recorded previously. Despite the bony collapse present in some cases, the Schmorl's nodes observed by Mooser were not present in the vertebrae examined in the present series.

In contrast to the osteoporosis of hyperparathyroidism (Hunter and Turnbull 1931, Jaffe 1940) or of hyperthyroidism (Follis 1953) there is no evidence that increased osteoclastic destruction is the factor responsible for the changed bone structure in the osteoporosis of Cushing's syndrome. Indeed, in the material that he studied, Follis was not able to find any osteoclasts at all! The diminished number of osteoblasts on the bone surfaces in the most severely osteoporotic cases, and the scarcity of osteoid borders, both indicate, however, that interference with osteoblastic bone formation is the important factor in the production of skeletal changes. This histological abnormality is, in fact, what might be expected from Albright's hypothesis that the effect of the abnormal or excessive adrenal hormones in Cushing's syndrome is to inhibit the synthetic metabolic activities of tissues. The maintenance of normal bone structure depends, ultimately, on a balance between osteoblastic bone formation and osteoclastic bone destruction. Any persistent disturbance of this balance in favour of destruction, whether an exaggeration of osteoclastic bone destruction or an inhibition of osteoblastic bone formation, would give rise to skeletal rarefaction. In Cushing's syndrome the second of these alternatives appears to be the one concerned.

While changes in the shafts of long bones are not as evident as those in vertebral bodies in Cushing's syndrome, it would be of great interest to examine bone from such situations, using the techniques of microradiography developed by Engström and Amprino (1950). Even in areas where osteoporosis was not evident, such investigations might be expected to show interference with the normally continuous process of formation and progressive calcification of bone in the Haversian systems of compact bone.

It is of interest to compare the skeletal changes in Cushing's syndrome in man with those produced experimentally in animals by the administration of either pituitary adrenocorticotrophic hormone or cortisone. Thus Becks et al. (1944) described inhibition of proliferation of cartilage cells and of osteoblasts in the region of the epiphysial plate in the bones of young rats following the administration of A.C.T.H. The effect of cortisone and of 17-hydroxycorticosterone-21-acetate on the growing bones of the rat has been described by Follis $(1951 b, 1952)$, while Sissons and Hadfield (1955) have studied the effect of cortisone on the growing bones of rats and rabbits. In the rabbit, cortisone inhibits the proliferation of the cartilage cells of the epiphysial plate, with reduction in the rate of longitudinal bone growth, even down to complete cessation. Osteoclastic activity is unimpaired, and progressive resorption of metaphysial trabeculae results from the inhibition of osteoblastic bone formation. Thus the skeletal position is exactly comparable with what is found in Cushing's syndrome. In the rat, cartilage proliferation is inhibited and longitudinal growth is diminished, but the effect on bone itself is inconstant. Sometimes resorption of metaphysial trabeculae is seen; at other times the balance between osteoblastic and osteoclastic activity is changed in the reverse direction and metaphysial trabeculae of abnormal density are produced.

The diminution in the reparative processes of fracture repair described in the present paper corresponds with the results of experimental work with cortisone. In rabbits, for example, Blunt et al. (1950) and Sissons and Hadfield (1951) have shown that administration of cortisone inhibits both cartilage proliferation and osteoblastic bone formation in the developing callus of experimental fractures. In the experimental fractures in cortisone-treated 
animals, moreover, the latter authors have described the same type of quiescent and degenerate cartilaginous tissue, showing little or no evidence of vascularisation, that is found in Cases 1,2 and 3 of the present paper.

\section{SUMMARY}

1. The bone changes in four autopsied cases of Cushing's syndrome are described. The changes take the form of osteoporosis, which is most marked in the spine and the ribs.

2. The osteoporosis results from impaired osteoblastic bone formation in the presence of a normal degree of osteoclastic bone resorption.

3. Histological abnormalities of fracture callus in Cushing's syndrome indicate interference with the proliferation of osteoblasts and cartilage cells and with the formation of new tissue by these cells.

4. The bone changes in Cushing's syndrome are comparable with those produced in experimental animals by the administration of A.C.T.H. or cortisone.

I am greatly indebted to Professor Dorothy Russell for access to pathological material and information from Cases 1, 2 and 3, to Dr E. F. Scowen and to Professor J. W. S. Blacklock for similar help with Case 4, and to $\mathrm{Dr} M$. H. Jupe for information regarding the radiological findings in Case 2. The radiographic part of the work was supported by the James Picker Foundation on the recommendation of the Committee on Radiology, National Academy of Sciences, the National Research Council of the United States of America.

\section{REFERENCES}

Albright, F. (1943): Cushing's Syndrome. Harvey Lectures, 38, 123.

Becks, H., Simpson, M. E., Choh Hao Li, and Evans, H. M. (1944): Effects of Adrenocorticotrophic Hormone (A.C.T.H.) on the Osseous System in Normal Rats. Endocrinology, 34, 305.

Blunt, J. W., Jun., Plotz, C. M., Lattes, R., Howes, E. L., Meyer, K., and Ragan, C. (1950): Effect of Cortisone on Experimental Fractures in the Rabbit. Proceedings of the Society for Experimental Biology and Medicine, 73, 678.

Crooke, A. C. (1935): A Change in the Basophil Cells of the Pituitary Gland Common to Conditions which Exhibit the Syndrome Attributed to Basophil Adenoma. Journal of Pathology and Bacteriology, 41, 339.

Cushing, H. (1932): The Basophil Adenomas of the Pituitary Body and their Clinical Manifestations (Pituitary Basophilism). Bulletin of the Johns Hopkins Hospital, 50, 137.

See also: Cushing, H. (1933): “ Dyspituitarism ": Twenty Years Later, with Special Consideration of Pituitary Adenomas. Archives of Internal Medicine, 51, 487.

Engström, A., and AMPrino, R. (1950): X-ray Diffraction and X-ray Absorption Studies of Immobilized Bones. Experientia, 6, 267.

Follis, R. H., Jun. (1951a): The Pathology of the Osseous Changes in Cushing's Syndrome in an Infant and in Adults. Bulletin of the Johns Hopkins Hospital, 88, 440.

FoluIs, R. H., Jun. (1951b): Effect of Cortisone on Growing Bones of the Rat. Proceedings of the Society for Experimental Biology and Medicine, 76, 722.

Follis, R. H., Jun. (1952): Effect of 17-Hydroxycorticosterone-21-Acetate on Growing Bones of the Rat. Bulletin of the Johns Hopkins Hospital, 90, 337.

Folus, R. H., Jun. (1953): Skeletal Changes Associated with Hyperthyroidism. Bulletin of the Johns Hopkins Hospital, 92, 405.

Hunter, D., and Turnbull, H. M. (1931): Hyperparathyroidism: Generalised Osteitis Fibrosa with Observations upon the Bones, the Parathyroid Tumours, and Normal Parathyroid Glands. British Journal of Surgery, 19, 203.

JAFFe, H. L. (1940): Hyperparathyroidism. Bulletin of the New York Academy of Medicine, 16, 291.

Lescher, F. G., and RobB-Smith, A. H. T. (1935): A Comparison of the Pituitary Basophilic Syndrome and the Adrenal Cortico-Genital Syndrome with a Report on the Pathology. Quarterly Journal of Medicine, N.S. 4, 23. Maclay, W. S., Stokes, A. B., and Russell, D. S. (1938): Mental Disorder in Cushing's Syndrome. Journal of Neurology and Psychiatry, N.S. 1, 110.

Mooser, H. (1920): Ein Fall von endogener Fettsucht mit hochgradiger Osteoporose. Ein Beitrag zur Pathologie der inneren Sekretion. Virchows Archiv für Pathologische Anatomie und Physiologie, 229, 247.

Rutishauser, E. (1933): Osteoporotische Fettsucht (Pituitary Basophilism). Deutsches Archiv für Klinische Medizin, 175, 640 .

Sissons, H. A., and HADFIELD, G. J. (1951): The Influence of Cortisone on the Repair of Experimental Fractures in the Rabbit. British Journal of Surgery, 39, 172.

Sissons, H. A., and Hadfield, G. J. (1955): The Influence of Cortisone on the Structure and Growth of Bone. Journal of Anatomy, 89, 69.

Vol. 38 B, NO. 1, fEBRUARY 1956 